\title{
SINERGIA
}

REVISTA DO INSTITUTO DE CIÊNCIAS ECONÔMICAS, ADMINISTRATIVAS E CONTÁBEIS (ICEAC)

\section{ESTUDO BIBLIOMÉTRICO DAS PRODUÇÕES CIENTÍCAS SOBRE ECONOMIA ECOLÓGICA, MULTIFUNCIONALIDADE DA AGRICULTURA E PESCA ARTESANAL}

\author{
DIANA MENDES CAJADO \\ ANTÔNIO JEOVAH DE ANDRADE MEIRELES** \\ FRANCISCO CASIMIRO FILHO"*
}

\begin{abstract}
RESUMO
O método bibliométrico corrobora para identificação das produções vinculadas aos periódicos de relevância da área de interesse. Além de conter um resultado quantitativo, apresenta o panorama da produção de forma especializada e temporal, ainda oportuniza ao pesquisador selecionar sua amostra para estudos do tipo review, e orienta a construção das bases teórico-conceituais em diversas áreas do conhecimento. $\mathrm{O}$ artigo traz como objetivo principal realizar o levantamento da produção científica sobre as categorias: pesca artesanal; multifuncionalidade da agricultura familiar e economia ecológica, além da identificação de possíveis correlações entre as categorias e caracterização do panorama da produção existente. Os gráficos de quantidade de publicações por ano, áreas de concentração da produção científica, foram os outputs considerados nesta pesquisa. Além disso, foram consideradas as variáveis por categoria: quantidade de artigos publicados, ano da primeira publicação, artigo mais citado e seu referente ano, pais de maior de produção, título da obra mais citada e número de citações. A plataforma utilizada para o levantamento dos resultados bibliométricos foi a Scopus em decorrência de sua característica interdisciplinar e difusão nos estudos desta natureza. As categorias foram inseridas e pesquisadas isoladamente e escrita em língua inglesa. O estudo mapeou a evolução das produções cientificas sobre das categorias economia ecológica, multifuncionalidade da agricultura familiar e pesca artesanal. Observou-se, de modo geral, que há maior incidência de produção científica a partir dos anos 2000, apesar da ocorrência de alguma oscilação. As três categorias apresentam em comum produção científica nas áreas de Meio ambiente e Ciências sociais.
\end{abstract}

Palavras-chave: Estudo bibliométrico. Economia ecológica. Review.

\section{ABSTRACT}

The bibliometric method corroborates to identify the productions linked to the relevant periodicals of interest. In addition to containing a quantitative result without itself, it presents the panorama of production in a spatial and temporal way, it also gives the researcher the opportunity to select his sample for review-type studies, in addition to guiding the construction of the theoretical-concepts bases in several areas of knowledge. The article's main objective is to carry out a survey of scientific production on the categories: Artisanal fishing; Multifunctionality of family farming and Ecological Economics, in addition to identifying possible correlations between categories and characterizing the panorama of existing production. The graphs of the number of publications per year, areas of concentration of scientific production were the outputs considered in this research. In addition, the variables by category were considered: number of articles published, year of first publication, most cited article and its referring year, country of greatest production, title of the most cited work and number of citations. The platform used by the survey of bibliometric results was Scopus due to its interdisciplinary characteristics and diffusion in studies of this nature. The categories were inserted and searched separately and written in English. The study mapped the evolution of scientific production in the categories Ecological Economy, Multifunctionality of family farming and artisanal fishing. It was generally observed that there is a greater incidence of scientific production from the 2000s, despite the occurrence of some fluctuation. The three categories have in common scientific production in the areas of Environment and Social Sciences.

Keywords: Bibliometric study. Ecological economics. Review.

Recebido em: 25-09-2019 Aceito em: 02-03-2020

\footnotetext{
"Doutora em Desenvolvimento e Meio Ambiente pela Universidade Federal do Ceará (UFC). Mestra em Economia Rural pela Universidade Federal do Ceará (UFC). Graduada em Engenharia de Pesca pela Universidade Federal do Ceará (UFC). E-mail: diana.mendes@famil.edu.br

" Doutor em Geografia pela Universidade de Barcelona. Professor do Departamento de Geografia da Universidade Federal do Ceará (UFC) e dos Programas de Pós-Graduação em Geografia e em Desenvolvimento e Meio Ambiente (PRODEMA).

" Doutor em Economia Aplicada pela Escola Superior de Agricultura Luiz de Queiroz da Universidade de São Paulo. Mestre em Ciências (Economia Aplicada) pela Universidade de São Paulo. Graduado em Engenharia Agronômica pela Universidade Federal do Ceará. Professor Associado da Universidade Federal do Ceará (UFC).
} 


\section{INTRODUÇÃO}

Em uma pesquisa, independente da escolha do tipo de abordagem, o levantamento do conhecimento acumulado sobre as temáticas que serão trabalhadas é fulcral. Contudo, há o recorrente risco de fazê-lo de maneira assistemática ou com insegurança sobre a amplitude que o levantamento tenha alcançado.

Neste sentido, o método bibliométrico corrobora para identificação das produções vinculadas aos periódicos de relevância da área de interesse. Além de conter um resultado quantitativo, apresenta o panorama da produção de forma especializada e temporal, e ainda oportuniza ao pesquisador selecionar sua amostra para estudos do tipo review e orientar a construção das bases teórico-conceituais nas diversas áreas do conhecimento.

Os métodos bibliométricos, por sua vez, vêm sendo aplicados não somente aos estudos cienciométricos e à avaliação da pesquisa em ciência e tecnologia (C\&T), mas também à análise de suas relações sociais e econômicas. Com efeito, a ciência, por ser uma força vigorosa na sociedade contemporânea, seu mapeamento e avaliação são questões consideradas cruciais. Uma forma de avaliação da pesquisa científica é aquela feita por pares. Essa avaliação é de natureza qualitativa, usada para julgar propostas de pesquisa, avaliar grupos de pesquisa, entre outros aspectos. Os indicadores bibliométricos, por sua vez, representam o aspecto quantitativo da atividade de avaliação (KOBASHI; SANTOS, 2006, p. 33).

A bibliometria pode auxiliar na identificação de tendências de crescimento do conhecimento em determinada disciplina, dispersão e obsolescências de campos científicos, autores e instituições mais produtivos, e periódicos mais utilizados na divulgação de pesquisas em determinada área do conhecimento (SOARES et. al., 2016).

"A bibliometria, como área de estudo da ciência da informação, tem um papel relevante na análise da produção científica de um país, uma vez que seus indicadores retratam o grau de desenvolvimento de uma área do conhecimento de um campo científico ou de saber" (ARAÚJO; ALVARENGA, 2011, p.51).

Em se tratando de estudos interdisciplinares, a bibliometria mostra-se uma interessante ferramenta, pois permite identificar produções cientificas que tragam propostas que amalgamam categorias analíticas. Característica esta que justificou a escolha desta ferramenta para o presente estudo, já que o artigo traz, como objetivo principal, realizar o levantamento da produção científica sobre as categorias: pesca artesanal; multifuncionalidade e economia ecológica, além de identificar possíveis correlações entre as categorias e caracterizar o panorama da produção existente.

\section{PESCA ARTESANAL, MULTIFUNCIONALIDADE DA AGRICULTURA FAMILIAR E ECONOMIA ECOLÓGICA: CONTEXTUALZIANDO O ESTUDO BIBLIOMÉTRICO}

$\mathrm{Na}$ Europa, o termo Multifuncionalidade da agricultura tem sua égide na Europa. Este termo foi inserido pela primeira vez, em 1993, pelo Comitê Europeu de Direito Rural (CEDR), preocupado em harmonizar a legislação agrícola dos países europeus, dando um conteúdo jurídico à noção imprecisa de agricultura sustentável. Sobre isso, tem-se as considerações de Carneiro e Maluf (2005), confirmando que o reconhecimento das múltiplas funções desempenhadas pela agricultura é produto de processos sociais em que uma ou outra função será mais valorizada pela respectiva sociedade. Isso faz com que certos elementos presentes na construção social europeia da Multifuncionalidade não recebam a mesma atenção ou sequer estejam presentes no Brasil.

Carneiro (2000), uma das primeiras pesquisadoras a escrever sobre a Multifuncionalidade da agricultura na realidade rural brasileira, juntamente com Cazella e Maluf, expressam que a multifuncionalidade permite identificar algumas dimensões da articulação da agricultura com as demais esferas da sociedade que até então "estavam à margem das análises e das lentes dos formuladores de políticas públicas".

Carneiro (2002) destaca, ainda, o aspecto operacional da Multifuncionalidade. Para ela, esta categoria contribui como um instrumento metodológico e de análise, possibilitando abordar e compreender o meio rural, sob uma visão holística, dando a esta categoria um status de teórico-metodológica.

Este caráter operacional da Multifuncionalidade aplicado aos entendimentos da agricultura como modo de vida, como agricultura familiar, acaba por iluminar possibilidades de seu uso para a pesca artesanal.

A pesca é uma das atividades mais antigas exercidas pelo homem, data do período anterior ao Neolítico. Os restos de cerâmica, cascas de ostras e mexilhões encontrados na Escandinávia, em período anterior ao Neolítico, atestam a importância dos moluscos na alimentação humana (DIEGUES, 2003).

Povos ou grupos sociais que praticam a pesca datam de eras pré-coloniais no Brasil. Ao longo dos anos, vão se reinventando e resistindo com base nas relações sociais e de produção, transformando os espaços que ocupam. Por meio de suas práticas, reafirmam saberes, culturas e identidades (CAJADO, 2017). 
Ao longo de toda a costa e nas águas interiores do país, é possível encontrar pessoas ou famílias que têm, na pesca artesanal, o exercício de uma atividade na qual se mesclam as condições objetivas de sua reprodução, como o acesso à alimentação e renda, com condições subjetivas, como o conhecimento tradicional sobre o meio natural e o trabalho fortemente condicionado por dinâmicas ambientais (PASQUOTTO e MIGUEL, 2005).

Tanto a pesca artesanal quanto a agricultura familiar alicerçam suas práticas socioeconômicas às condições providas pela natureza, construindo, de modo intergeracional, relações com os ecossistemas aos quais estão integrados. Elementos estes que o modo de mensuração econômico vigente não apresenta métodos possíveis de valorá-los.

A economia neoclássica, ao não considerar as relações sociais de poder e a economia como dependente da natureza, estaria produzindo uma visão de mundo distorcida, na qual os mecanismos de preços acabariam com o problema da escassez por meio da substituição dos fatores e do progresso tecnológico. Nesse sentido, seria incapaz de lidar com a incerteza e com a complexidade dos sistemas econômico-ecológicos e com os dilemas socioambientais (SAES; ROMEIRO, 2018 p. 132-133).

Neste contexto, buscam-se, na Economia Ecológica, as possibilidades de compreensão da pesca artesanal enquanto modo de vida.

Para a Economia Ecológica, a questão é conceber a economia-atividade como sistema aberto dentro do ecossistema. Nessa ótica, não se entende que haja criação de riqueza. Há, sim, transformação (metabolismo) de matéria e energia de baixa entropia em matéria e energia de alta entropia - como estabelecem as incontornáveis leis da termodinâmica. Essa perspectiva significa a visão ecológica da economia. Ou seja, corresponde a dizer que existirá uma escala máxima sustentável do sistema econômico com respeito ao ecossistema (CAVALCANTE, 2015, p. 169).

Na perceptiva da Economia Ecológica, esta proposta pode ser pensada a partir de Daly e Farley (2016), quando afirmam que o sistema econômico é um subsistema de um sistema maior finito, a biosfera, e partem do pressuposto de que este sistema não pode suportar um sistema econômico em expansão contínua.

\section{METODOLOGIA}

A escolha do método é fundamental para o alcance do objetivo da pesquisa. Desta feita, quando se pretende identificar o referencial bibliográfico produzido a respeito do assunto em investigação, a análise bibliométrica corresponde a um método bastante eficiente (FERNANDES; LIMA, 2019).

A plataforma utilizada para o levantamento dos resultados bibliométricos foi a Scopus, em decorrência de sua característica interdisciplinar e difusão nos estudos desta natureza. As categorias foram inseridas e pesquisadas isoladamente e escritas em língua inglesa.

A base Scopus foi lançada pela editora Elsevier em 2004. No ano de 2013, contava com, aproximadamente, 21.000 títulos de mais de 5.000 editoras internacionais. Com atualização diária, a cobertura se dá desde 1823 e realizam-se as contagens de citações desde 1996 (SILVA; GRÁCIO, 2017).

Para a categoria de Economia Ecológica, optou-se em realizar um intervalo de corte temporal das buscas a partir de 1988, ano do surgimento da International Society of Ecological Economics (ISEE). Fundada como resultado de um workshop realizado em Barcelona em 1987, cuja temática era a integração da economia e da ecologia (SAES; ROMEIRO, 2018). Já para as categorias Multifuncionalidade da agricultura familiar e Pesca artesanal, o intervalo temporal foi do tipo aberto.

Os gráficos de quantidade de publicações por ano, áreas de concentração da produção científica, foram os outputs considerados nesta pesquisa. Foram consideradas, também, as variáveis por categoria: quantidade de artigos publicados, ano da primeira publicação, artigo mais citado e seu referente ano, país de maior de produção, título da obra mais citada e número de citações.

\section{RESULTADOS E DISCUSSÂO}

Com relação à produção cientifica sobre Economia Ecológica, observou-se uma tendência de aumento a partir dos anos de 1994. Esta questão pode ser atribuída à efervescência do debate sobre os problemas ambientais e a idealização do Desenvolvimento Sustentável. Contudo, atinge o pico em 2012, com 26 publicações, de um total de 254 publicações registradas na Scopus. 
Gráfico 1 - Evolução temporal das produções científicas em EE.

Documents by year

Scopus

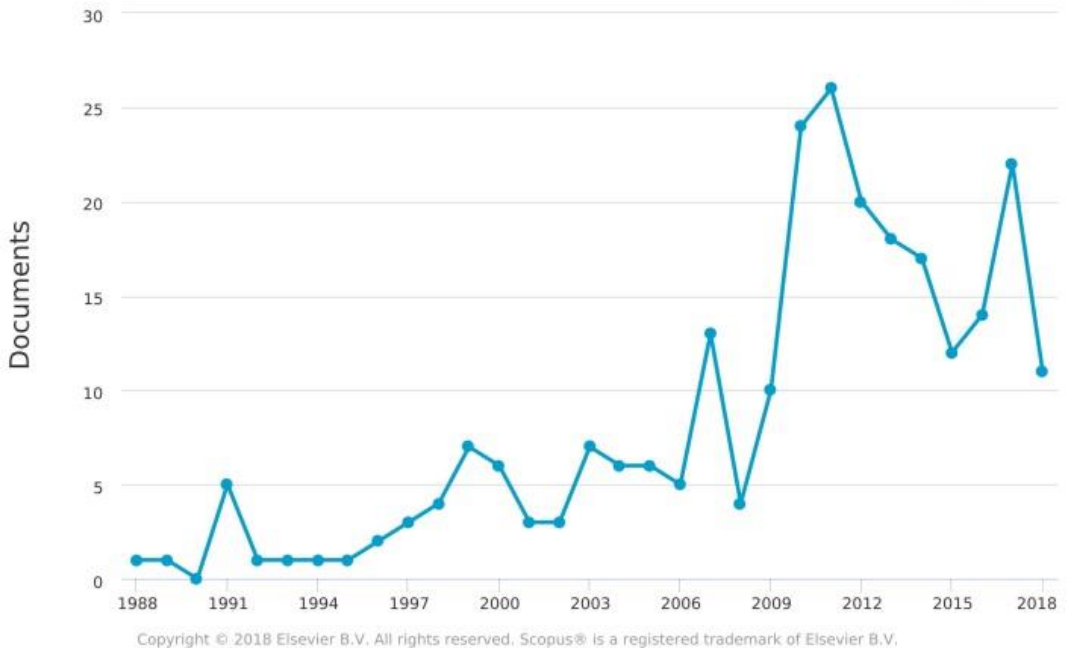

Fonte: Scopus (2018).

No tocante ao assunto por área de interesse (gráfico 2), apresentou-se bastante diversificada, refletindo a disseminação da temática por diversas áreas num total de 11 , refletindo o caráter intrinsecamente interdisciplinar, sobressaindo, em ordem de incidência, a áreas de Meio ambiente $(20,7 \%)$, Ciências Sociais (16,4\%) e Engenharia (13\%).

Gráfico 2 - Distribuição da produção científica em EE por assunto de interesse.

Documents by subject area

Scopus

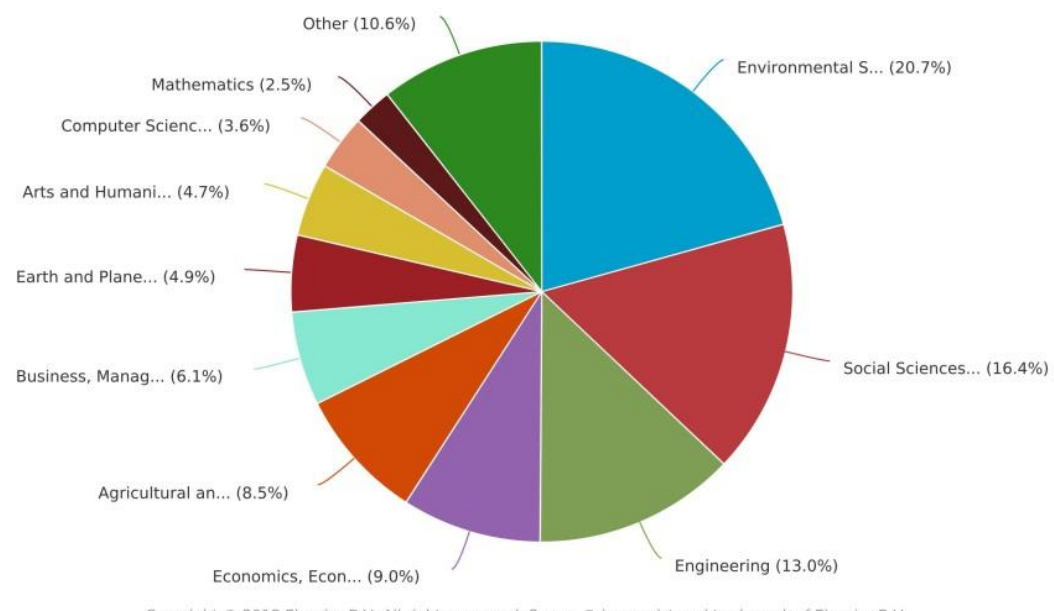

Fonte: Scopus (2018).

A produção acadêmica acerca da Multifuncionalidade da agricultura familiar, de acordo com o gráfico 3 , é a mais recente das três categorias mapeadas, data de 2001 a primeira publicação. Isso pode ser atribuído a duas questões: primeiro ao fato de esta categoria ter sua égide no cenário das políticas de ordenamento rural territorial europeu, logo, levando um tempo para os acadêmicos se apropriarem deste fenômeno; e outra remete à popularização em escala mundial da Multifuncionalidade da agricultura, que se deu em 1992, durante a Eco-92, ainda sem um conceito propriamente definido, ainda sem a visão da agricultura familiar (CAZELLA; MATTEI, 2002). Atinge seu ápice em 2007 com 3 publicações, repetindo este comportamento em 2009 e, desde então, apresentando uma tendência de queda nas publicações. 
Gráfico 3 - Evolução temporal das produções científicas em Multifuncionalidade da agricultura. Documents by year

Scopus

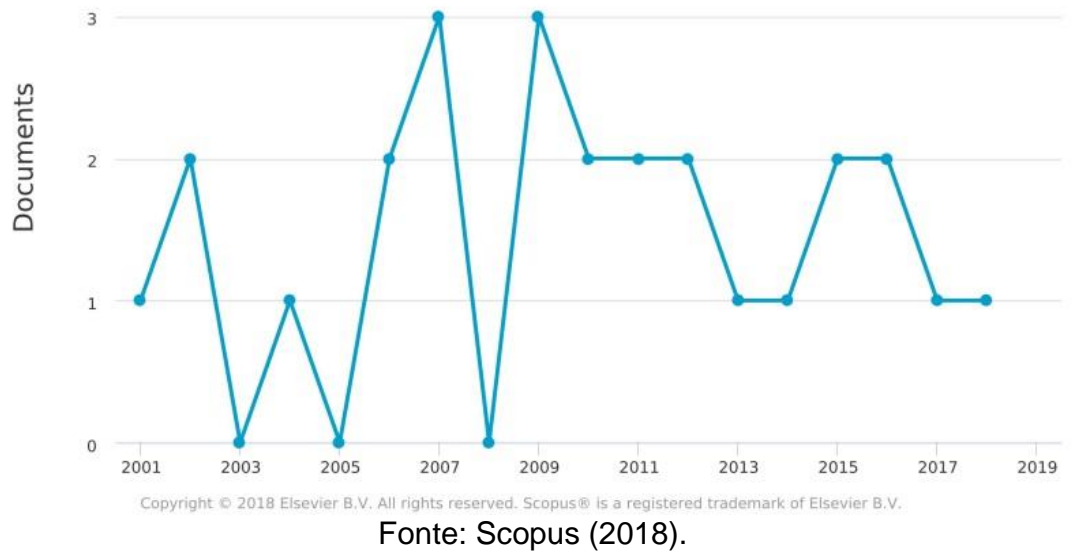

Quando à data que marca o início de seus registros acadêmicos na plataforma, pode-se associar ao fato da trajetória desta categoria no contexto brasileiro ter seu marco inicial nos anos 2000, por meio do desenvolvimento de uma rede interinstitucional ${ }^{1}$ de pesquisadores, a qual contou com o apoio do Núcleo de Estudos e Agricultura e Desenvolvimento do Ministério do Desenvolvimento Agrário (Nead/MDA) e do Instituto Interamericano de Cooperação para a Agricultura (IICA) (CAZELLA, BONNAL e MALUF, 2009).

A rede se constituiu tendo como referência o enfoque da multifuncionalidade da agricultura então em plano florescimento em várias partes do mundo, com destaque para a Europa Ocidental e particularmente, a França. A perspectiva era desenvolver estudos e pesquisas visando à apropriação e a operacionalização deste enfoque nas circunstâncias próprias da agricultura familiar brasileira (CAZELLA, BONNAL e MALUF, 2009, p. 17).

Com apenas 26 publicações identificadas pela plataforma Scopus, esta produção tem sua concentração na área de Agricultura e Ciências Biológicas com 33,7\%, seguido das áreas de Meio ambiente com $21 \%$ e Ciências Sociais, com $14,1 \%$, perfazendo um somatório de $68,8 \%$ das produções identificadas para a categoria.

Gráfico 4 - Distribuição da produção científica em Multifuncionalidade da agricultura familiar por área de interesse.

Documents by subject area

Scopus

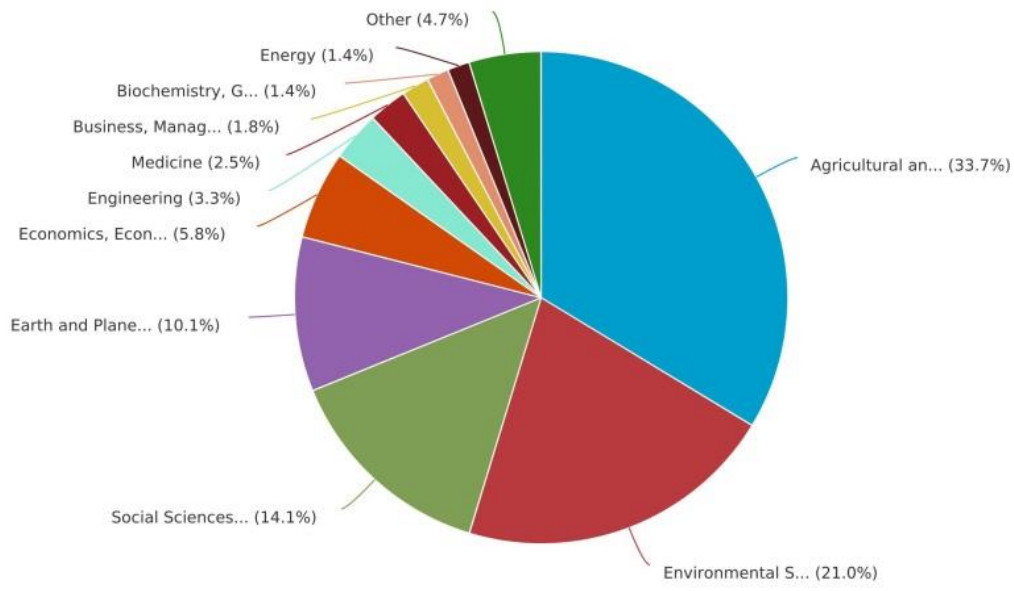

Fonte: Scopus (2018).

\footnotetext{
${ }^{1}$ A rede é composta por pesquisadores das instituições: UFRRJ-CPDA (coord.), UFSC/CCA, UFRGS/PGDR, Embrapa-CNPAM, USP/Esalq, Ufes, UFCG e UFPA (Brasil). Cirad e Inra (França).
} 
Com relação à pesca artesanal, apresentou-se como a categoria mais antiga em relação à origem de suas publicações, data seu primeiro registro na Scopus de 1979, conforme gráfico 5 . O gráfico mostra, ainda, que de 1980 a 1987 não foi registrada nenhuma publicação com enfoque para a pesca artesanal.

Contudo, a partir dos anos 2002, a produção cientifica da área apresenta um comportamento de aumento, tendo seu pico em 2016, com 18 artigos, dentre as 134 produções indexadas a Scopus. Observase a possibilidade de em 2018 superar este quantitativo, pois, até o primeiro semestre, já atingiu o total de 17 publicações.

Gráfico 5 - Evolução temporal das produções científicas em pesca

artesanal

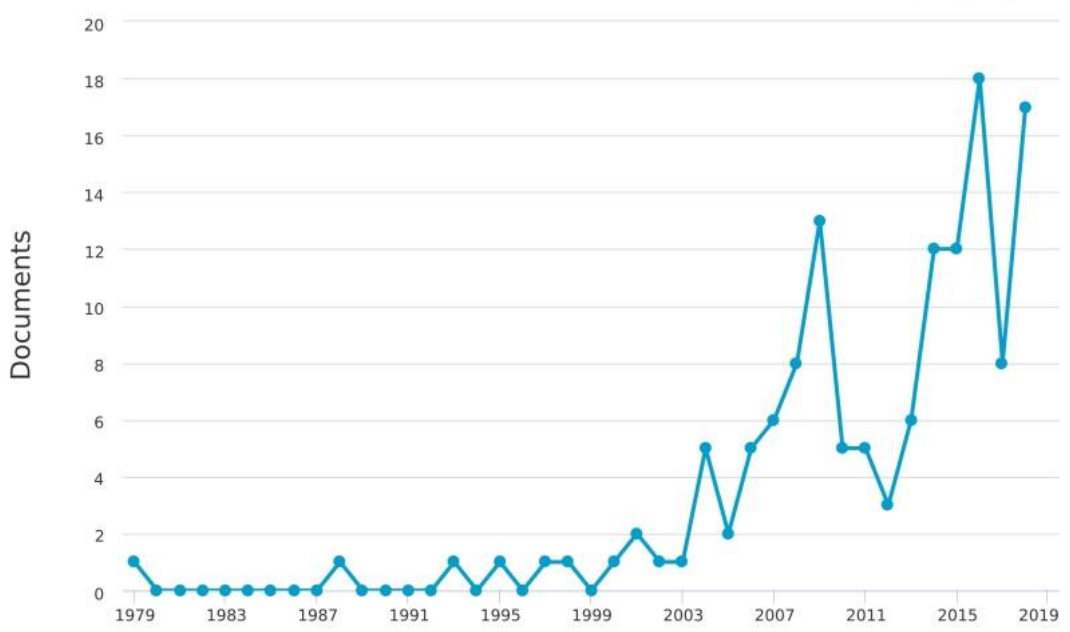

Fonte: Scopus (2018)

Comportamento semelhante ao identificado para a categoria de Multifuncionalidade da agricultura manifesta-se na distribuição por assunto de interesse para a pesca artesanal. De modo que apresenta $85,3 \%$ de sua produção cientifica concentrada nestas áreas: ciências Sociais $(34,1 \%)$, agricultura e ciências biológicas (31,7\%) e meio ambiente (19,5\%), as mesmas para a pesca artesanal.

Gráfico 6 - Distribuição da produção científica em pesca artesanal por assunto de interesse.

Documents by subject area

Scopus

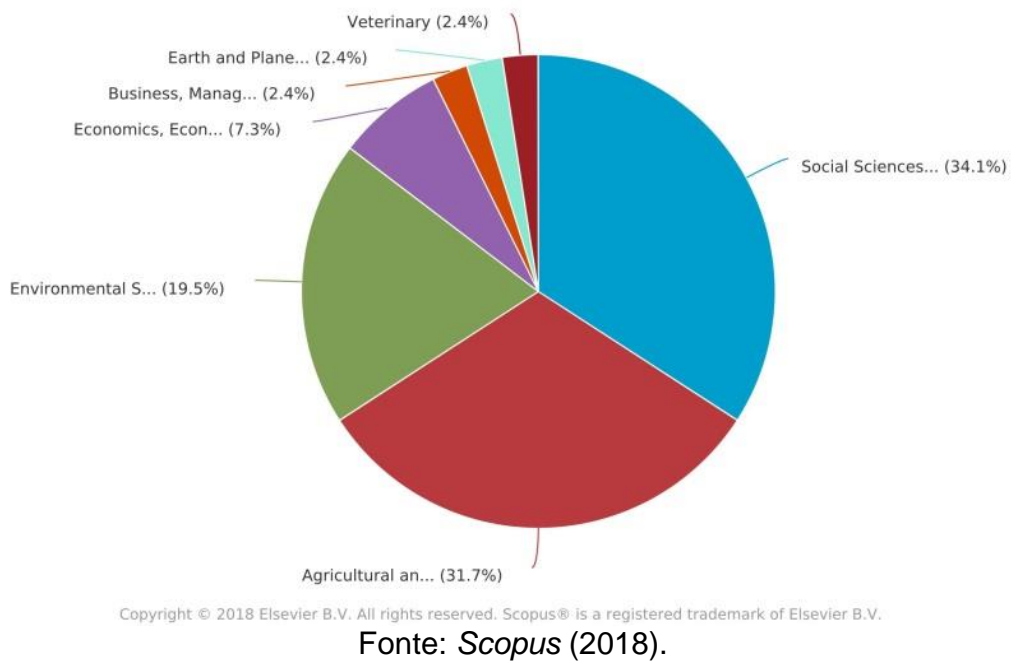

Ao realizar a tentativa de mapear alguma publicação cientifica que articulasse as 3 categorias em uma pesquisa, não se identificou-se nenhum estudo com este caráter. De modo que aponta um caminho ainda não explorado pelos pesquisadores das áreas de interesse em que se concentram as categorias de análise abordadas neste estudo bibliométrico. 
No quadro 1, segue uma síntese das informações apresentadas, acrescidas da identificação do país de maior produção por categoria, título e ano do artigo mais citados, além do número de citações. Quadro 1 - Síntese das variáveis levantadas pela bibliometria.

Quadro 1 - Síntese das variáveis levantadas pela bibliometria

\begin{tabular}{|c|c|c|c|c|c|c|}
\hline Categoria & $\begin{array}{l}\text { Quantidade } \\
\text { de artigos } \\
\text { publicados }\end{array}$ & $\begin{array}{c}\text { Ano da } \\
\text { primeira } \\
\text { publicação }\end{array}$ & $\begin{array}{l}\text { País de } \\
\text { maior } \\
\text { produção }\end{array}$ & $\begin{array}{c}\text { Área de } \\
\text { concentração } \\
\text { mais } \\
\text { publicada }\end{array}$ & $\begin{array}{c}\text { Artigos } \\
\text { mais } \\
\text { citados/ano }\end{array}$ & $\begin{array}{l}\text { Número } \\
\text { de } \\
\text { citações }\end{array}$ \\
\hline Pesca artesanal & 138 & 1979 & Brasil & $\begin{array}{c}\text { Ciências } \\
\text { sociais }\end{array}$ & $\begin{array}{c}\text { Effects of } \\
\text { Artisanal } \\
\text { Fishing on } \\
\text { Caribbean } \\
\text { Coral Reefs, } \\
(2004) .\end{array}$ & 131 \\
\hline $\begin{array}{l}\text { Multifuncionalidade } \\
\text { da agricultura } \\
\text { familiar }\end{array}$ & 26 & 2001 & $\begin{array}{l}\text { Países } \\
\text { Baixos } \\
\text { (Europa) }\end{array}$ & $\begin{array}{l}\text { Agricultura e } \\
\text { ciências } \\
\text { biológicas }\end{array}$ & $\begin{array}{c}\text { Why is } \\
\text { diversification } \\
\text { an attractive } \\
\text { farm } \\
\text { adjustment } \\
\text { strategy? } \\
\text { Insights from } \\
\text { Texas } \\
\text { farmers and } \\
\text { ranchers, } \\
\text { (2009). }\end{array}$ & 107 \\
\hline $\begin{array}{l}\text { Economia } \\
\text { Ecológica }\end{array}$ & 254 & 1988 & China & $\begin{array}{c}\text { Meio } \\
\text { ambiente }\end{array}$ & $\begin{array}{c}\text { Tracking the } \\
\text { ecological } \\
\text { overshoot of } \\
\text { the human } \\
\text { economy, } \\
\text { (2002). }\end{array}$ & 624 \\
\hline
\end{tabular}

Fonte: Dados da pesquisa (2018).

\section{CONCLUSÕES}

O estudo mapeou a evolução das produções cientificas sobre as categorias Economia Ecológica, Multifuncionalidade da Agricultura Familiar e Pesca Artesanal. Observou-se, de modo geral, que há maior incidência de produção científica a partir dos anos 2000, apesar da ocorrência de alguma oscilação.

As três categorias apresentam em comum produção científica nas áreas de Meio ambiente e Ciências sociais. Sendo que a Multifuncionalidade da agricultura familiar e a pesca artesanal apresentaram, também como área em comum, a Agricultura e Ciências biológicas, ou seja, toda a produção cientifica destas concentra-se nas mesmas áreas do conhecimento. Isso sinaliza a possibilidade de estudos correlacionando as três categorias.

O Brasil foi identificado como o país que mais concentra produção científica sobre pesca artesanal na plataforma considerada para a pesquisa, no caso a Scopus. Contudo, é necessário mencionar que esta categoria já possui uma vasta produção distribuída em outras plataformas.

Constatou-se que é na Europa onde se concentram os estudos sobre a Multifuncionalidade da agricultura, algo de certa forma já esperado, tendo em vista ter sua origem na França e estendido rapidamente pela Europa, sendo base ainda, na atualidade, para políticas agrícolas europeias. Já com relação à Economia Ecológica, o país que mais tem publicado é a China, fato que inspira novas pesquisas.

A utilização das bibliometria possibilitou gerar um banco de dados bibliográfico que servirá de amostra para pesquisa de análise de conteúdo dos trabalhos desenvolvidos nas categorias ora levantadas. 


\section{REFERÊNCIAS}

ARAÚJO, R, F; L, AVARENGA. A bibliometria na pesquisa científica da pós-graduação brasileira de 1987 a 2007 . R. Eletr. Bibliotecon. Ci. Inf., Florianópolis, v. 16, n. 31, p. 51-70, 2011.

CAJADO, D. M,; SOBRAL, F. M.; MEIRELES, A. J. de A. Zoneamento agroecossistêmico e social: uma compreensão sistêmica sobre a comunidade Apiques, Assentamento Maceió, Itapipoca-CE. GAIA SCIENTIA, João Pessoa, v. 11, n. 1, p.307-319, ano 2017.

CARNEIRO, M. J. Política Pública e Agricultura Familiar: uma Leitura do Pronaf. Projeto Rurbano, 2000. 120p.

CARNEIRO, M. J. Multifuncionalidade da agricultura e ruralidades: uma abordagem comparativa. In: MOREIRA, Roberto. J; COSTA, Luíz, F. de C. (org.) Mundo rural e cultura. Rio de Janeiro: MAUAD, 2002, p. 223-240.

CARNEIRO. J; MALUF. R. S. Multifuncionalidade da agricultura familiar. In: FILHO, Flávio. B. B. (org.). Agricultura familiar e desenvolvimento territorial em debate. v. 5. Brasília: UNB, 2005, 43-58.

CAZELLA, Ademar. A; BONNAL, Philippe; MALUF, Renato, S. Agricultura Familiar: multifuncionalidade e desenvolvimento territorial no Brasil, Rio de Janeiro: Mauad X, 2009.

DALY, H; JOSHUA, F. Economia Ecológica. São Paulo: Annablume Cidadania e Meio Ambiente, 2016.

DIEGUES, Antônio. C. A interdisciplinaridade nos estudos do mar: O papel das ciências sociais. Conferência proferida na XV Semana de Oceanografia, Instituto Oceanográfico da USP, Outubro, 2003. Disponível em: http://www.usp.br/nupaub/interdis.pdf. Acesso: em 15 mai. 2018.

FERNANDES, Ivana. L. C; LIMA, Patrícia. V.P. S. Análise bibliométrica da produção acadêmica sobre bem-estra subjetivo e acesso a água em comunidades rurais. R. gest. sust. ambient., Florianópolis, v. 8, n. 4, p. 42-56, out/dez. 2019.

KOBASHI, Nair, Y; SANTOS, Raimundo, M.N. Institucionalização da pesquisa científica no Brasil: cartografia temática e de redes sociais por meio de técnicas bibliométricas. TransInformação, Campinas, v. 18, n. 1 p. 27-36, jan./abr., 2006.

PASQUOTTO, V. F; MIGUEL, L. de A. Pesca artesanal e enfoque sistêmico: uma atualização necessária. In: Agricultura familiar e abordagem sistêmica. Aracaju: Sociedade brasileira de sistemas de produção, 2005, p. 61-80.

SAES, Beatriz, M; ROMEIRO, Ademar, R. O debate metodológico na economia ecológica: indefinição ou pluralismo?. Nova econ., Belo Horizonte, v. 28, n. 1, p. 127-153, Apr. 2018. Disponível em: http://www.scielo.br/scielo.php?script=sci_arttext\&pid=S010363512018000100127\&lng=en\&nrm=iso.Acesso em: 05 ago. 2018.

SILVA, DEISE. D; GRÁCIO, MARIA CLAUDIA, C. Índice h de Hirsch: análise comparativa entre as bases de dados Scopus, Web of Science e Google Acadêmico. Em Questão, Porto Alegre, v. 23, p. 196-212, Edição Especial 5 EBBC, 2017.

SOARES, Patrícia, B; et. al. Análise bibliométrica da produção científica brasileira sobre Tecnologia de Construção e Edificações na base de dados Web of Science. Ambiente Construído, Porto Alegre, v. 16, n. 1, p. 175-185, jan./mar. 2016. Disponível em: http://www.scielo.br/scielo.php?pid=S1413-41522012000100002\&script=sci_arttext. Acesso em: 24 mar. 2019 